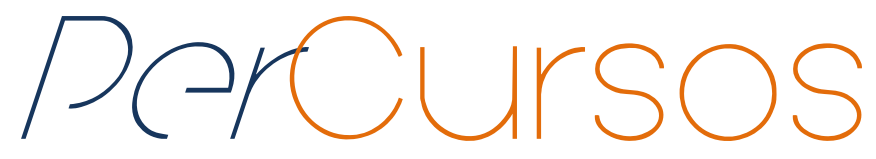

\title{
Por trás das lentes: agressão conjugal descrita por homens indiciados por violência doméstica
}

\section{Resumo}

Esta pesquisa teve como base um enfoque relacional que buscou investigar as concepções sobre relacionamentos, violência doméstica, relações de gêneros e perspectivas de vidas, retratadas por oito homens indiciados por praticar o crime de violência doméstica (Lei Maria da Penha). Os dados foram coletados através de entrevistas e de autorrelatos dos participantes durante suas explanações em um grupo terapêutico, mediado por duas psicólogas e uma estagiária de psicologia. A partir do material textual originado foi realizada análise de conteúdo temático categorial, que resultou na identificação de três categorias, sendo elas: concepções de gênero; perspectiva de vida; e conflitos relacionais. Foi possível averiguar alguns padrões de comportamentos de gêneros tradicionalistas, pautados por uma (pseudo) autoridade masculina sobre a feminina. As dificuldades dos participantes permearam, principalmente, pela falta de habilidades sociais para resolver os problemas cotidianos, bem como pela ausência de perspectiva de vida. Essa última, sendo muitas vezes associada à baixa autoestima. Avalia-se que o atendimento ao agressor conjugal permite aos pesquisadores ampliar o enfoque sobre o fenômeno da violência doméstica, além de suscitar novas reflexões a partir de outra ótica.

Palavras-chave: Violência Doméstica; Violência Conjugal; Relações de Gênero; Autores da Violência; Homens Indiciados.

\author{
Bettieli Barboza da Silveira \\ Mestre em Psicologia pela \\ Universidade Federal de Santa \\ Catarina - UFSC. \\ Brasil \\ bettieli.bs@gmail.com
}

\section{Eduardo José Legal}

Doutor em Psicologia pela Universidade de São Paulo - USP. Professor da Universidade do Vale do Itajaí - UNIVALI. Brasil edujlegal@gmail.com

\section{Para citar este artigo:}

SILVEIRA, Bettieli Barboza da; LEGAL, Eduardo José. Por trás das lentes: agressão conjugal descrita por homens indiciados por violência doméstica. Revista PerCursos, Florianópolis, v. 17, n.35, p. 223 - 245 , set./dez. 2016.

DOI: $10.5965 / 1984724617352016223$

http://dx.doi.org/10.5965/1984724617352016223 


\title{
Behind the lens: aggression marital described by indicted men for domestic violence
}

\begin{abstract}
This research was based on a relational approach that investigated the conceptions about relationships, domestic violence, gender relations and perspectives of life portrayed by eight men indicted for practicing the crime of domestic violence (Maria da Penha Law). Data were collected through interviews and self-reports of the participants for their participation in a therapeutic group mediated by two psychologists and a psychology intern. From the textual material originated was held thematic content analysis, which resulted in the identification of three categories, namely: gender conceptions; life expectancy; and relational conflicts. It was possible to find out some patterns of traditionalist gender behavior, guided by a male (pseudo) authority over women. The difficulties of the participants permeated mainly by the lack of social skills to solve everyday problems, as well as the lack of life perspective. The latter is often associated with low selfesteem. It evaluates the care marital aggressor allows researchers to expand the focus on the phenomenon of domestic violence, as well as generate new reflections from another perspective.
\end{abstract}

Keywords: Domestic Violence; Conjugal Violence; Gender Relations; Perpetrators of Violence; Indicted Men. 


\section{Introdução}

"A melhor coisa a fazer é criar você mesmo uma nova maneira de usar sua força." (SELIGMAN, 2011, p. 51)

As pesquisas científicas envolvendo o estudo da violência doméstica pela ótica do agressor conjugal têm evoluído muito nos últimos anos. Diversos autores (PADOVANI, WILLIAMS, 2011; CORTEZ, SOUZA, 2010; CORTEZ, SOUZA, QUEIRÓS, 2010) em Psicologia vêm tentando ampliar o escopo de conhecimento sobre esta temática, e, por vezes o fazem através de relatos sobre atuações práticas, como: grupo terapêutico, atendimento clínico, serviços da rede pública, entre outros. A inserção desses e de outros pesquisadores no reduto da violência doméstica contribui com a desmistificação na perspectiva de se investir apenas na compreensão acerca do sofrimento da mulher. Tão importante quanto o investimento e interesse científico sobre a vítima é o investimento sobre as singularidades do agressor conjugal. Sendo assim, amplia-se o olhar sobre o fenômeno e torna-se possível contemplar aspectos relevantes da relação, abordando as especificidades de ambos os pontos de vista.

Na esfera social-nacional, a violência doméstica incorporou-se aos movimentos feministas de forma mais intensa entre as décadas de 70 e 80, também nesta época, o governo propôs as primeiras políticas públicas voltadas a esta temática. No reduto científico, a partir do ano 2000 houve um significativo aumento na produção especializada, em que se trata o assunto como uma questão complexa, multifacetada e que viola os direitos humanos das mulheres vitimizadas (GADONI-COSTA; DELL'AGLIO, 2009; FONSECA, RIBEIRO, LEAL, 2012; ROVINSKI, 2004). A expansão e a dimensão da violência doméstica no Brasil podem ser observadas tanto nas literaturas acima citadas, quanto nos veículos midiáticos, que por vezes discorrem sobre tal problemática. De um tabu a uma questão de saúde pública, nota-se mais envolvimento de diversas áreas do saber, bem como um investimento em formação profissional vislumbrando uma desconstrução de mitos e preconceitos (LIMA, 2008). 
Entende-se que a violência doméstica é constituída por qualquer ação ou omissão baseada no gênero, que possa causar morte, lesão, sofrimento físico, sexual, psicológico e dano moral ou patrimonial no âmbito da unidade doméstica, da família ou em qualquer relação íntima de afeto na qual o agressor conviva ou tenha convivido com a ofendida, independentemente de coabitação (BRASIL, 2006). Dessa forma, pode-se considerar um grande passo quando uma mulher consegue efetivar a denúncia da violência sofrida, pois se trata de um momento singular em que ela precisa de apoio e acompanhamento, haja vista que nem sempre ela está "pronta” para sair da situação de violência (MONTEIRO, SOUZA, 2007). Nesse sentido, Pasinato (2006) salienta a importância do primeiro atendimento dado à mulher e do papel que esse momento passar a ter sobre as decisões que ela tomará em relação ao seu futuro. Mas, e quanto ao agressor? O que fazer com ele? "Vigiar e punir", como diria Foucault (1987), ou intervir em busca de uma nova perspectiva aos casos de violência doméstica, eis a dúvida.

Ao investigar as ações e intervenções perante homens indiciados por violência doméstica, identificou-se em uma revisão bibliográfica que o quantitativo e relativo material publicado ainda é pouco, porém consistente e crescente (PADOVANI, WILLIAMS, 2009; CORTEZ, PADOVANI, WILLIAMS, 2005; PADOVANI, WILLIAMS, 2011; CORTEZ, SOUZA, 2010). Trata-se do caminhar da comunidade científica a fim de reforçar as relevantes iniciativas de se promover o tema do investimento perante o agressor conjugal.

As intervenções com homens indiciados ainda perpassam o crescimento e expansão necessários, porém alguns estudos (BOONZAIER, 2008; CORTEZ, SOUZA, 2008; WOOD, 2004) já destacam que uma das principais dificuldades para esta prática é o contato com esses homens. Dentre as razões disparadoras para a recusa está o fato do sujeito não se considerar um agressor; não se sentir seguro para um diálogo com a(o) psicóloga(o); não querer falar sobre o assunto; e não ter tempo para "isso" (entrevista/grupos terapêuticos). No entanto, cabe ressaltar que a atuação junto a esta parcela da população é de extrema importância, uma vez que se aumenta a qualidade da 
compreensão e intervenção com o casal envolvido a partir de uma proposta que articule as percepções e avaliações de ambos.

Com vistas a uma intervençao que trabalhasse acerca da reflexão, da modificação de comportamentos inadequados e de risco, bem como a melhoria da qualidade de vida, optou-se pela utilização da Teoria Cognitiva Comportamental - TCC (LUCÂNIA et al., 2009). Segundo Habigzang e colaboradores (2009), a TCC tem apresentado melhores resultados na aplicação em casos de violência em comparação a outras abordagens nãofocais. Além disso, acrescenta-se a alta eficácia da Teoria como modelo interventivo psicológico, com ênfase na reestruturação de crenças disfuncionais. Conceitualmente, a TCC parte do pressuposto teórico de que as mudanças terapêuticas ocorrem na medida em que os pensamentos disfuncionais se alteram. Assim, trabalha-se com a definição de objetivos de modo específico, considerando as problemáticas e dificuldades apresentadas ao terapeuta (BAHLS, NAVOLAR, 2004).

Com vistas à problematização do tema, esse estudo visa relatar uma experiência com um grupo terapêutico de homens indiciados por violência doméstica. Trata-se de um relato descritivo, que se oferece à crítica e à apreciação da comunidade científica a respeito de um modelo interventivo embasado pela Teoria Cognitiva Comportamental. Esta pesquisa foi executada em parceria com o Poder Judiciário de uma Comarca de Santa Catarina, de onde os indiciados foram encaminhados para participar do grupo, orientados por duas psicólogas. Além das intervenções propriamente ditas, as psicólogas também colaboravam com informações a respeito da evolução terapêutica dos mesmos durante o processo, emitidas através de um parecer técnico direcionado à Juíza e aos autos processuais de cada participante. Faz-se a ressalva de que essa proposta de intervenção visa reforçar as investigações sobre a aplicabilidade do conceito de Justiça Restaurativa. Segundo Pinto (2011), o mundo precisa avançar para um sistema flexível de justiça criminal, com condutas adequadas à variedade de transgressões e de sujeitos envolvidos. Isso contempla um salto de qualidade do sistema, convertendo-o para um sistema multiportas que ofereça respostas diferentes e mais adequadas à criminalidade. 


\section{Método - Delineamento}

Esse estudo caracteriza-se como uma pesquisa descritiva e exploratória, visa expandir a descrição e exemplificação da violência doméstica revista por diferentes ângulos e perspectivas. Orientada pelos pressupostos da natureza qualitativa (OLABUÉNAGA, 2012), almejando identificar as particularidades do fenômeno, amparados pelo pensamento indutivo. Priorizou-se a profundidade dos dados obtidos, e a exposição mediante o corte transversal realizado, ou seja, aquela realidade naquele período de tempo (SAMPIERI et al, 2006).

Quanto aos participantes, configura-se um quadro com o estudo da intervenção de um grupo com: a) oito homens; b) faixa etária entre 18 e 64 anos; c) indiciados por violência doméstica (Lei Maria da Penha - 11.340/06); d) residentes no mesmo município, no estado de Santa Catarina; e que, e) aceitaram participar do grupo terapêutico, consentindo tal permissão para divulgação dos dados para fins acadêmicos e de pesquisa por intermédio do Termo de Consentimento Livre e Esclarecido. Quanto à caracterização de cada membro do grupo, observa-se na tabela abaixo uma breve descrição, resguardados por todos os aspectos éticos descritos na Resolução CNS 422/12.

\begin{tabular}{|l|l|l|l|}
\hline Participante & Idade & Escolaridade & Tipo de violência \\
\hline P1 & 18 & E. Médio Incompleto & Física, psicológica e patrimonial \\
\hline P2 & 64 & Superior Completo & Física, psicológica, patrimonial e sexual \\
\hline P3 & 21 & Superior Incompleto & Física e psicológica \\
\hline P4 & 45 & E. Médio Completo & Física e psicológica \\
\hline P5 & 58 & Analfabeto & Física e psicológica \\
\hline P6 & 32 & E. Médio Completo & Psicológica \\
\hline P7 & 35 & E. Médio Incompleto & Psicológica \\
\hline P8 & 40 & E. Médio Completo & Física e psicológica \\
\hline
\end{tabular}

Tabela 1 - Dados de caracterização dos membros do grupo. 
Em relação às especificidades dos participantes, de forma unânime foi relatado o sofrimento de algum tipo de violência ao longo da vida. Em sua maioria (7), predominou a verbalização sobre negligência paterna na infância, fome, mais de dois irmãos na família e situação de pobreza até o início da vida adulta. A escolaridade se mostrou diversificada, alguns (3) creditaram a falta de incentivo para concluir os estudos à necessidade de trabalhar, devido ao contexto socioeconômico da família. A renda média entre os participantes variou de $\mathrm{R} \$ 1.500,00$ a $\mathrm{R} \$ 2.500,00$, sendo que cinco deles faziam "bicos" como vendedores ambulantes, denominados por eles como trabalhos esporádicos, considerando a característica turística da região que habitam. Já quanto aos crimes supostamente (haja vista que ainda eram indiciados) praticados, tem-se no grupo apenas um membro suspeito de praticar o crime contra a mãe, os demais são relacionados às companheiras (esposas, namoradas).

De acordo com Lima (2008), é preciso conceber a violência como um fenômeno complexo, carente de análise de várias esferas. Múltiplos fatores favorecem a prática da violência, tais como: pobreza, histórico familiar, abandono dos pais, conflitos na relação conjugal, álcool e outras drogas. Fatores que, importante destacar, favorecem, mas não são determinantes para a prática violenta (BITTAR, NAKANO, 2011).

O grupo terapêutico para o qual os participantes foram encaminhados foi idealizado por uma Juíza de Direito, assim, o projeto caracterizou-se pela parceria entre o Poder Judiciário Catarinense e uma entidade filantrópica responsável pela realização dos atendimentos e das intervenções. Ressalta-se que, além disso, para dar conta da demanda, foi criado um Programa específico para o atendimento das vítimas e dos indiciados por violência doméstica e familiar.

\section{Procedimentos}

A estrutura de trabalho do Programa de atendimento aos homens indiciados iniciava com um convite para uma conversa individual, a fim de expor todas as formas de atendimento disponibilizadas (atendimento individual e grupo terapêutico a indiciados e 
vítimas), bem como a intenção das profissionais em incluí-los no grupo terapêutico. Diante do aceite em participar do grupo, o diálogo prosseguia guiado por um roteiro de entrevista semiestruturada com o intuito de melhor conhecê-los. Nesse momento, visavase a obtenção de dados sociodemográficos, características inerentes à questão de gênero, divisão de papéis no seio familiar, aspectos específicos do relacionamento com a vítima (do processo), histórico de violência, redes sociais de apoio, trabalho, estudo e demais vínculos significativos para o sujeito.

Devido à alta demanda de casos judiciais e, por consequência, de atendimentos a serem realizados, os grupos foram estruturados para acontecerem durante cinco encontros de forma quinzenal. Ao final, os participantes interessados em continuar no grupo terapêutico eram incentivados a frequentar os coletivos seguintes, de maneira que fosse possível fomentar a consistência e atenção às necessidades singulares de cada membro. A intervenção grupal descrita nesse artigo foi conduzida por uma estagiária de Psicologia (orientada pelo docente responsável) e supervisionada pela psicóloga da instituição (coordenadora do Programa). Para tanto, estruturaram-se encontros com duração aproximada de 1h3omin, seguidos, ao final, por um breve questionário, a ser respondido pelos participantes, com perguntas abertas elaboradas de acordo com as propostas do diálogo do dia, bem como anotações livres.

A distribuição das propostas trabalhadas no grupo se deu, principalmente, com base no Treino de Habilidades Sociais, inerente à Teoria Cognitiva Comportamental. Desse modo, conforme as singularidades coletivas e as demandas individuais compreendidas através da entrevista inicial, foi elaborada uma tabela com as atividades planejadas (revistas a cada encontro) para esse grupo. Observa-se na tabela abaixo (Tabela 2): 


\begin{tabular}{|c|c|c|}
\hline Encontros & Temas & Procedimentos \\
\hline Primeiro & $\begin{array}{l}\text { Integração/rapport. } \\
\text { Dessensibilização } \\
\text { sistemática. }\end{array}$ & $\begin{array}{l}\text { - Apresentação, objetivos do trabalho e } \\
\text { contrato grupal. } \\
\text { - Dinâmica: "apresentando o outro como se } \\
\text { fosse eu”. } \\
\text { - Confecção do desenho de uma árvore (raiz) } \\
\text { e exploração da infância dos participantes. }\end{array}$ \\
\hline Segundo & $\begin{array}{l}\text { Comportamentos } \\
\text { transgeracionais e } \\
\text { Pensamentos automáticos. }\end{array}$ & $\begin{array}{l}\text { - Continuação e exploração do desenho da } \\
\text { árvore (tronco), que simboliza a } \\
\text { adolescência. } \\
\text { - Reflexão sobre as vivências similares entre } \\
\text { os familiares. } \\
\text { - Identificar os pensamentos automáticos de } \\
\text { cada um. }\end{array}$ \\
\hline Terceiro & $\begin{array}{l}\text { Habilidades sociais. } \\
\text { Projeto de vida. }\end{array}$ & $\begin{array}{l}\text { - Desenho das ramificações e galhos da } \\
\text { árvore, simbolizando as escolhas da vida. } \\
\text { - Debate sobre projeto de vida, metas e } \\
\text { objetivos. } \\
\text { - Pensamento divergente. } \\
\text { - Vídeo "Tião Simpatia e a Lei Maria da } \\
\text { Penha" para auxiliar no treino de habilidades } \\
\text { assertivas. }\end{array}$ \\
\hline Quarto & $\begin{array}{l}\text { Habilidades sociais. Inversão } \\
\text { de papéis. } \\
\text { Flecha descendente. }\end{array}$ & $\begin{array}{l}\text { - Desenho das folhas da árvore } \\
\text { representando as primeiras escolhas do } \\
\text { projeto recriado. } \\
\text { - Habilidade: resiliência. } \\
\text { - Discussão sobre inversão de papéis e } \\
\text { empatia. } \\
\text { - Técnica da flecha descendente sobre o fato } \\
\text { que culminou no processo criminal. }\end{array}$ \\
\hline Quinto & $\begin{array}{l}\text { Orientação para seguimento } \\
\text { dos projetos. } \\
\text { Síntese integrativa. } \\
\text { Avaliação do grupo } \\
\text { (feedback). }\end{array}$ & $\begin{array}{l}\text { - Desenho da árvore florescendo; escolhas } \\
\text { concluídas, novas perspectivas. } \\
\text { - Protagonismo, autonomia. } \\
\text { - Perspectiva de vida. } \\
\text { - Fechamento do grupo, feedback, } \\
\text { encaminhamentos e despedida. }\end{array}$ \\
\hline
\end{tabular}

Tabela 2 - Propostas elaboradas para o grupo.

Para a análise dos dados provenientes dos procedimentos supracitados foram realizadas leituras e transcrições, tanto da entrevista inicial como do material produzido 
pelos participantes durante o andamento do grupo. Tais processos foram necessários para alcançar o objetivo de identificar os principais aspectos inerentes ao conteúdo declarativo dos entrevistados. O conteúdo originado foi organizado de modo que fossem localizadas categorias que contemplassem objetivos específicos indicados anteriormente. Para tanto, foi utilizada a técnica de análise temática categorial, que busca identificar e analisar os temas que compõem o texto, ou seja, as unidades de significação encontradas no material textual (BARDIN, 2010).

\section{Resultados e discussão}

Para a realização da análise de conteúdo contou-se com o amparo dos pressupostos da Teoria Cognitiva Comportamental e com o referencial teórico dos fenômenos investigados. Dessa forma, o conteúdo oriundo das intervenções (dados brutos) compôs o corpus de pesquisa. Observando as dimensões teóricas, criaram-se três grandes categorias, uma que reúne as descrições de práticas e concepções sobre gênero, denominada "Concepções de gênero"; uma relacionada às situações atuais de vida de cada um, "Perspectiva de vida"; e a terceira que é referente ao conflito que há na relação, chamada "Conflitos relacionais". Entende-se que estas categorias, mesmo interligadas, abrangem aspectos fundamentais para a melhor compreensão do fenômeno da violência doméstica e que, segundo a literatura, merecem ser discutidas com ênfase.

a) Concepções de gênero

A análise do conteúdo revela o compartilhamento de diversas concepções relacionadas "às atribuições de um homem e de uma mulher" no contexto doméstico e familiar. Nos relatos se revelou a ausência de diálogos para resolver os atritos entre os casais, seguidos de concepções arcaicas nas quais a mulher não possuía os direitos, afinal "ela não tinha o direito de levantar a voz para mim, que sou o homem da casa (P7)". Ademais, também foi possível notar participantes com pensamentos que continham menos traços de machismo ou diferença de gênero, porém mais características de falta de habilidade social, como afirmou P1: "como não tive pai, minha mãe foi pai e mãe ao 
mesmo tempo. Então, tipo assim, não trato mal minha mulher. O meu problema é a minha raiva, não sei lidar com ela".

A delimitação de função social a partir do gênero é um processo de variadas influências transgeracionais, caracterizado, muitas vezes, pela repetição de práticas de gerações anteriores (FALCKE et al., 2009). A “masculinidade” pautada pela agressividade perante situações estressoras denota, segundo Santos (2012), uma falha de comunicação entre o casal. Por outro lado, Ribeiro et al (2009) destacam que a permanência da mulher na relação violenta se dá pela incapacidade de visualizar outras possibilidades de vida, reforçando os pressupostos de ausência de projeto de vida, descrito por Seligman (2011).

De modo geral, alguns membros do grupo expressaram uma postura que muitas vezes é contraditória, por exemplo: "é óbvio que ela tem que cozinhar, lavar, passar, essas coisas de casa. Mas, também precisa trabalhar fora, em função de mulher, tipo secretária, atendente, eu sozinho não dou conta de pagar tudo (P2)". Por outro lado, também pontuam que "eu não sou machista, machista é aquele cara que não deixa a mulher trabalhar. Eu deixo! (Р3)" e, "lá em casa é tudo dividido, mas eu não sei fazer muitas coisas, então fico mais com o trabalho bruto, lavo carro, conserto coisas, e ela com as coisas delicadas, tipo cozinhar (P6)". Na relação conjugal violenta não é difícil notar que as assimetrias de poder são, em grande parte, pautadas pelas diferenças de gênero (BITTAR, NAKANO, 2011). Segundo as autoras, a divisão de papéis no reduto familiar é permeada por um compartilhar de direitos e deveres desiguais, definindo-se relações de subordinação e dominação.

No que condiz às possibilidades de autonomia da companheira em sair para programações com amigas, por exemplo, o debate foi grande e repleto de divergências. Segundo P4, "não dá para proibir, e não quero que ela saia sem contar pra mim. Então eu libero. Também jogo meu futebol e ela não liga. As vezes até vai junto”. Já P5 é enfático "nós temos muito o que fazer, tem que acordar cedo e plantar (casal de agricultores). Então se ficar de fuxico e tricô com as outras, não aguenta me ajudar na lavoura.". Corroborado por P8, que diz que "mulher quando se reúnem todas é problema, só aprontam e fofocam dos maridos. Prefiro que ela só saia comigo junto ou com as crianças, sozinha não é bom 
né?!”. De acordo com Piscitelli (2002), o papel da mulher construído socialmente perpassa o reduto de dependência em relação ao parceiro conjugal, sendo que esse homem representa a figura do provedor financeiro e material. Tais diferenças entre os gêneros atravessam a hierarquia designada a cada um, historicamente visualizada pela dócil e sutil mulher, contraposta pela agressividade e coragem do homem (RIBEIRO et al, 2009).

O conteúdo revela que para que as elas sejam consideradas boas esposas, namoradas, e mães, devem cuidar da casa, zelar pelo bem estar do companheiro, entender e fazer as "as funções de uma mulher (P5)". A dúvida aparece quando, por fim, eles são questionados sobre tais funções, de onde elas surgiram no cotidiano desses casais e como se sustentam. De acordo com P1 "de tanto a senhora perguntar aos outros caras aqui sobre isso eu já nem sei mais o que responder, pensando bem, isso (machismo) já é coisa velha né? E eu não gostaria de ver meu pai, que nem tive, fazer isso com minha mãe, por exemplo". Nessa situação de inversão de papéis percebe-se que todos se permitiram pouco a pouco a refletir, sem necessariamente concordar, sobre seus argumentos e concepções. No caso de $\mathrm{P} 3$, ele afirma que simplesmente "fui respondendo (as perguntas) assim naturalmente, mas quando cheguei na última senti, sei lá, um pouco de estranhamento. Não sei dizer a partir de onde comecei a pensar assim, que estranho! Meio preconceituoso o que eu respondi antes né? (Demais questões)".

Embora todos os participantes concordem que existiu e existe uma evolução histórica e social do papel da mulher na contemporaneidade, eles ainda relutam e insistem em praticar os comportamentos que eles mesmos identificam como "do tempo dos nossos pais (P4)". Verifica-se que os casais convivem com uma ausência de diálogo para decidir as questões diárias inerentes à administração do lar, portanto prevalece o posicionamento e/ou vontade do homem. Do contrário, instauram-se brigas e discussões. Apesar disso, nota-se que todas as companheiras (com exceção da mãe/vítima processual de um dos participantes, que é aposentada) exercem atividades renumeradas fora de casa, possuem rede social de amigas, e são independentes financeiramente. O que, de certa forma, contrasta com os achados teóricos que versam sobre os muitos casos em que as mulheres ocupavam-se de tarefas domésticas e, por consequência disso, não 
detinham renda, culminando na dependência econômica e permanência na relação violenta (RIBEIRO et al, 2009). Além disso, elementos como o medo, o constrangimento e a dependência emocional são descritos por Garbin e colaboradores (2006) como motivos de não ação frente à situação de agressão.

b) Perspectiva de vida

Em relação aos projetos de vida que todos levam atualmente, surgiram diversas manifestações de insegurança e de falta de perspectiva de vida. Evidenciadas através de relatos sobre situações de trabalho, de estudo, de vivência ou não com a companheira (vítima processual) e de novos relacionamentos. Segundo Seligman (2011) é preciso pensar na vida de modo positivo, a preocupação do ser humano não deve direcionar-se apenas para as fraquezas e insucessos, e sim depositar toda força e energia para as qualidades e potencialidades passíveis de aprimoramento.

Um exemplo intrínseco à temática de perspectiva de vida ocorreu durante o segundo encontro, quando foi proposto que todos elaborassem e tentassem realizar uma meta a curto prazo, sendo que no coletivo seguinte a atividade seria compartilhada. Percebeu-se sucesso em quase todos os membros (7), sendo que um justificou a não realização por falta de organização, solicitando posteriormente um encontro individual para auxiliá-lo nesse planejamento. Dentre os exitosos na tarefa, destaca-se a fala de P7 “consegui ir jantar fora nesta semana, fui numa churrascaria e achei o máximo! Mas, vendo o P4 conseguir dar entrada numa moto, quero fazer um objetivo maior no próximo exercício!”.

O participante $\left(\mathrm{P}_{5}\right)$ que não conseguiu realizar a tarefa justificou seu insucesso dizendo que "estava com o dinheiro contado para mostrar para a senhora, esse foi meu plano, guardar dinheiro! Mas, um dia antes de vir aqui minha mulher passou mal e tive gastos com remédios que eu não imaginava que teria." Imprevistos acontecem e dificuldades sempre nos serão apresentadas ao longo da vida, assim que, observa-se o quão fundamental é o trabalho acerca do desenvolvimento de resiliência e de pensamento divergente. Reforça-se, também, com esse exercício a importância de se investir nas habilidades sociais de cada participante, que na maioria das vezes são 
subjugadas por eles mesmos. Em relação a tais habilidades, P6 conta que "eu escolhi fazer algo que sempre quis e nunca achei que eu conseguiria, por que sou meio bruto, sem jeito. Levei meu filho num parque que está aqui na cidade, passamos o dia lá, foi ótimo".

Constituem-se como habilidades sociais uma classe de comportamentos com grande potencial de suscitar consequências reforçadoras para o indivíduo, sendo que a intervenção em programas educacionais é de grande valia quando as condições de aprendizagem da pessoa não a permitiram desenvolver tais habilidades ao longo da vida (DEL PRETTE, DEL PRETTE, 2010). Embasados pela TCC, muitos terapeutas propõem o Treino de Habilidades Sociais a seus clientes, técnica que contribui significativamente para a melhora na comunicação e resolução de problemas conjugais (BECK, 1988/1995; CORDOVA, JACOBSON, 1999; SARDINHA, FALCONE, FERREIRA, 2009).

Por fim, observa-se que conseguir planejar a vida estruturando passo a passo as escolhas não é algo palpável e factível a todos. Nota-se que o grupo aponta como principais dificuldades para almejar objetivos na vida a falta de habilidades sociais assertivas e de planejamento. Evidencia-se tal perspectiva através da fala de P2, ao dizer que "eu vou lá e decido que vou fazer tal coisa, e na hora dá errado. Aí eu explodo! Preciso aprender a controlar a raiva, e isso é muito difícil para mim. Já até perdi emprego por isso". A agressividade é um comportamento comum para os membros do grupo diante de adversidades ou imprevistos, pois assim como $\mathrm{P}_{2}$, os demais também teceram comentários em referência a esse fato, segundo $\mathrm{P}_{5}$ "desde moleque sou assim meio bronco, revoltado com qualquer coisa. Não lembro de ter sido diferente. Se discordo da minha mulher, por exemplo, eu já me revolto. Ela diz que não sei conversar". De acordo com P8: "acho que não sou um cara desorganizado, mas me sinto frustrado quando sou contrariado ou quando tenho algum problema. Desde pequeno sou assim. Muitas vezes desisto do que quero por isso, porque acho que não vou conseguir".

As configurações de vida que os participantes expuseram durante os relatos demonstraram pouca ou nenhuma estrutura de projeto de vida. Percebe-se que, apesar das dificuldades descritas em lidar com as diferenças de gênero e com as conquistas das mulheres na sociedade, eles ainda parecem confusos e em períodos de transições. Os 
ajustamentos em relação ao lugar que eles, enquanto companheiros, ocupam na vida delas ainda causa desentendimentos que podem ser desencadeadores de conflitos, conforme identificado em outras pesquisas (DANTAS-BERGER, GIFFIN, 2005; GIFFIN, 2002).

A dinâmica relacionada às novas estruturas e modelos de vida em casal é encarada como um desafio para os membros do grupo. Identifica-se no discurso de todos os participantes, a dificuldade em planejar-se independente do relacionamento com suas companheiras. Por vezes é notório observar as falas em relação às dificuldades em reelaborar rotas e caminhos para atingir os objetivos que são acometidos por imprevistos. Tais deficiências em se reorganizar evidenciam a falta de habilidades sociais em lidar com adversidades, o que também reforça a importância de projetos como esse, de buscar algo para além da punição ao agressor conjugal. Apesar do comprometimento brasileiro em adotar determinadas políticas públicas para o combate à violência doméstica, tais ações ainda são pequenas e tímidas se comparadas à proporção de casos que ocorrem diariamente. Carecemos, enquanto país, de garantir direitos, dignidade e respeito às vítimas, sem olvidar do adequado tratamento que os agressores conjugais necessitam (RIBEIRO et al, 2009).

\section{c) Conflitos relacionais}

Dentre os motivos para brigas e discussões que os participantes relataram ter com suas companheiras/mãe/namoradas, destaca-se como foco a discordância diante das decisões cotidianas que envolvem vaidade, como a roupa que elas vão vestir. Observa-se que é considerado um problema, "um motivo para ficar de olho (P3)" quando a mulher se veste de modo diferenciado ou vai ao salão de beleza sem ter nenhum evento importante. Segundo P1, "A gente fica com uma pulga atrás da orelha né?! Não dá pra confiar totalmente, se não o cara é passado pra trás". Bem como o ciúme e a posse sobre as escolhas diárias de suas parceiras, eles também evidenciam a insegurança e o medo de serem traídos, "ah se eu descobrisse que ela pulou a cerca... Nem sei o que eu faria doutora! Coisa boa não seria! (P4)". 
No estudo de Oliveira e Gomes (2011) foram analisados 54 artigos nacionais que versavam sobre práticas envolvendo homens e violência conjugal; nesses textos, percebeu-se que, em geral, os homens veem a violência como condenável, mas tolerável ao ser aplicada em "mulheres que gostam de apanhar", quando despertado o "instinto" do gênero masculino, em situações de “educação da mulher", dentre outras inadmissíveis afirmativas. Quanto às justificativas mais comuns observadas na teoria para a prática violenta, destacam-se: o ciúme, a infidelidade, dependência financeira, dependência química, trabalho da mulher externo à casa , desemprego do homem, dentre outros (ROSA et al., 2008; ALVIM, SOUZA, 2005; OLIVEIRA, GOMES, 2011).

Os comportamentos que os participantes apontam como prejudiciais e estressores da relação com suas companheiras são geralmente relacionados a discordâncias que inferem sobre as escolhas alheias (que roupa vestir, com quais amigas pode sair, contato de um colega de trabalho). Porém, geralmente são descritos por eles em forma de reclamação, seguido de um pedido para que as psicólogas lhes entendam e concordem com seus pensamentos, conforme evidenciado na fala de $\mathrm{P} 2$, "se ela não me provocasse tanto seria muito melhor! Ela discorda de mim e a gente briga! Mas é aquela coisa, é complicado para o homem tolerar certas coisas, a senhora não acha?!”, e corroborado por P7 "eu sinto que somos tipo gato e rato! Tipo, se ela tá doente e não vai trabalhar, tem que avisar à colega e não ao folgado do cara que trabalha com ela. Não dá pra criar essas intimidades de ligar pra ele, não é mesmo?!”.

Em referência aos relatos de agressão e intimidação verbal, muitos (6) afirmaram desconhecer que violência psicológica seria uma das formas de violência das quais haviam sido indiciados. Com exceção de P6, que dizia que "esse (violência psicológica) é o primeiro passo até o momento em que se perde o controle e se agride fisicamente. Não foi o meu caso, mas mais um pouco seria, eu já não suportava mais esse jogo de humilhações", e de P1, que ratifica: "Eu sabia que se xingar e se humilhar era crime. Na verdade nem precisava ser né?! Quando a gente chega nesse ponto é por que acabou o respeito, aí não tem como seguir junto. O problema é o sentimento, a gente gosta né? Ou acha que gosta!". Dos que desconheciam tal tipificação de violência, destaca-se a fala de P3, em que enfatiza no 
diálogo o uso do álcool, "eu achava que essas brigas verbais eram tipo 'violência alcoólica'. Brigávamos em decorrência do meu excesso de bebida. Eu bebo, pois tenho uma rotina muito estressante, e ela não bebia, então discutíamos por isso". Nesse sentido, P5 reforça “Meu pai brigava e minha mãe discutia até se calar. Hoje lá em casa é igual. O problema é que não parei na 'briga de boca' e me dói demais quando penso que bati nela por conta da cachaça".

A violência psicológica caracteriza-se por toda ação ou omissão que acarrete danos à autoestima, à identidade ou ao desenvolvimento humano (DAY et al., 2003; FERRANTE, SANTOS, VIEIRA, 2009). Sobre tal modalidade de violência, Saffiotti e Almeira (1995) cunharam um termo a ser utilizado quando são observadas situações de dominação masculina, chamado "síndrome do pequeno poder". Em síntese, o termo se refere à reação masculina de colocar-se superior às suas companheiras, de modo a compensar a sensação de impotência que percebem em outros contextos que convivem, como o trabalho e classe social.

Dentre as produções investigadas, nota-se que em diversas pesquisas os autores buscam incluir estudos que discorram sobre a identificação de fatores relacionados ao uso da violência do homem contra a mulher. Nesse sentido, dos principais fatores elencados se destacam a naturalização de valores patriarcais, o histórico familiar de violência, baixa autoestima (de ambos os atores da relação), o uso de drogas lícitas e ilícitas, as dificuldades financeiras do casal, além do histórico da dominação masculina sobre a mulher (GADONI-COSTA; ZUCATTI; DELL'AGLIO, 2011; CORTEZ, SOUZA, QUEIRÓS, 2010).

Reforça-se a premissa de que é fundamental incluir debates e treinos que trabalhem as habilidades sociais de indiciados por violência doméstica. Segundo Oliveira (2010), sugere-se o desenvolvimento de características que permitam ao sujeito a capacidade de raciocinar sobre aquilo que ninguém mais está pensando, o que envolve fluidez de ideias, fazer novas combinações, olhar para novas perspectivas (contemplar o outro lado da "moeda"), vasculhar outros mundos, descobrir novas formas de busca e, enfim, despertar o espírito de colaboração. Ou, quem sabe, seria melhor dizer que é 
preciso primar pela redefinição do foco para além da situação de violência e contemplar uma postura macro estrutural.

\section{Considerações finais}

Os dados fornecidos pelos participantes através das intervenções propostas possibilitaram avaliar algumas características específicas e singulares das suas relações conjugais. Ressalta-se como maior desencadeador de violência, evidenciado nos relatos dos membros do grupo, a dificuldade em realizar diálogos entre o casal, bem como as insistências masculinas de posse e controle sobre as escolhas das mulheres. Esses padrões comportamentais são expressos por todos os participantes, em menor e maior proporção. Entende-se, também, que as verbalizações evidenciaram concordâncias entre os homens, principalmente no que tange às dificuldades em lidar com diferenças de desejos e vontades no relacionamento, às insuficientes habilidades perante as discordâncias sobre escolhas, e às precárias estruturações de planejamento de vida.

Vale ressaltar que esse estudo aponta o predomínio da violência psicológica, entrelaçada com outros tipos de agressão, apesar do desconhecimento de muitos sobre a definição do que é tal prática. Enquanto preditores do ato violento, destaca-se nesse grupo o uso de álcool, a baixa autoestima, a falta de habilidades sociais e o histórico de violência familiar. Considerada um fenômeno complexo, multifacetado e que requer atenção multidisciplinar, a violência doméstica caminha em prol da responsabilização dos agressores, bem como da desconstrução da crença irracional de que há supremacia de gêneros (BRASIL, 2011).

Quanto às limitações dessa pesquisa, faz-se o destaque ao número de encontros e de tempo disponíveis para a realização das atividades e das intervenções. Tal perspectiva reforça a importância de se criar e/ou subsidiar, através de políticas públicas, outros programas de atendimento à problemática da violência doméstica. Para suprir a demanda de agressores e vítimas conjugais que carecem de ações sociais é necessário maior investimento das entidades e gestores públicos. O direcionamento do foco carece 
ultrapassar a fase de tratamento, adentrar ao campo da prevenção da violência e da promoção de saúde. Por fim, admite-se que o contingente analisado restringiu-se a um grupo de oito homens indiciados; apesar disso, comemora-se positivamente o potencial de atenção individual e coletiva aos membros. Acredita-se que a oportunidade de fala livre, de expressão de ideias, de integração e identificação de uns com os outros, certamente configura-se como um diferencial do trabalho.

Destaca-se a importância de identificar as variáveis relacionadas às situações de violência doméstica e familiar, assim como os fatores associados a tais práticas delituosas. Os dados relativos ao histórico de violência familiar tanto de agressores quanto das vítimas suscitam reflexões sobre a relevância de se propor estudos com foco mais amplo sobre a família desse casal, expandindo-se para filhos, sogros, pais e demais parentes próximos. Nessa ótica, sugere-se, também, a criação de outros programas municipais responsáveis por intervenções com famílias em situação de violência, bem como a capacitação de profissionais que venham a lidar com tais problemáticas.

O percurso para que a violência doméstica passe a ser uma realidade abolida ainda é longo, quiçá utópico. Para que tal perspectiva aconteça, um bom início para a extensa caminhada são as delegacias especializadas, consideradas "o primeiro passo para o combate à violência”. Dessa forma, o investimento em policiais, em políticas públicas, e nos serviços da rede de assistência são uma realidade necessária. Estima-se que esse estudo contribua para a luta contra a violência doméstica, e para as demais pesquisas que, como essa, primam por uma realidade em que esse tipo de relato não seja mais verbalizado em sociedade.

\section{Referências}

ALVIM, Simone Ferreira; SOUZA, Lídio de. Violência conjugal em uma perspectiva relacional: homens e mulheres agredidos/agressores. Psicologia: teoria e prática, v. 7, n. 2, p. 171-206, 2005. 
BAHLS, Saint-Clair; NAVOLAR, Ariana Bassetti Borba. Terapia cognitivo-comportamentais: conceitos e pressupostos teóricos. Psico UTP online Revista Eletrônica de Psicologia, Curitiba, n. 04, 2004.

BARDIN, Laurence. Análise de conteúdo (1977). Tradução de Luís Antero Reto e Augusto Pinheiro. Lisboa: Edições, v. 70, 2010.

BECK, Aaron Temkin. Para além do amor: como os casais podem superar os desentendimentos, resolver os conflitos e encontrar uma solução para os problemas de relacionamento através da terapia cognitiva. Tradução: P. Froés, Rio de Janeiro: Rosa dos Tempos (Trabalho original publicado em 1989), 1995.

BITTAR, Daniela Borges; NAKANO, Ana Márcia Spanó. Violência intrafamiliar: análise da história de vida de mães agressoras e toxicodependentes no contexto da família de origem. Texto \& Contexto-Enfermagem, v. 20, n. 1, p. 17-24, 2011.

BOONZAIER, Floretta. 'If the Man Says you Must Sit, Then you Must Sit': The Relational Construction of Woman Abuse: Gender, Subjectivity and Violence. Feminism \& Psychology, 18(2), 183-206, 2008.

BRASIL. Lei 11.340, de 7 de agosto de 2006. Regulamenta os termos do § 80 do art. 226 da Constituição Federal e estabelece diretrizes da Convenção sobre a Eliminação de Todas as Formas de Violência contra a Mulher. 2006. Disponível em:

<http://www.planalto.gov.br/ccivil_03/_ato2004-2006/2006/lei/11340.htm>. Acesso em: 31 ago. 2016.

BRASIL. SECRETARIA DE POLÍTICAS PARA MULHERES - SECRETARIA DE POLÍTICAS PARA MULHERES. Diretrizes para Implementação dos Serviços de Responsabilização e Educação dos Agressores, 2011.

CORDOVA, James; JACOBSON, Neil. Crise de casais. Em D. H. Barlow (Orgs.), Manual clínico dos transtornos psicológicos.2ed.). Porto Alegre: Artmed, 1999. p.535-567.

CORTEZ, Mirian Béccheri; PADOVANI, Ricardo da Costa; WILLIAMS, Lúcia Cavalcanti de Albuquerque. Terapia de grupo cognitivo-comportamental com agressores conjugais. Estud. psicol.Campinas, v. 22, n. 1, p. 13-21, 2005.

CORTEZ, Mirian Béccheri; SOUZA, Lídio de. A violência conjugal na perspectiva de homens denunciados por suas parceiras. Arquivos brasileiros de psicologia, v. 62, n. 2, p. 129-142, 2010. 
CORTEZ, Mirian Béccheri.; SOUZA, Lidio. de. Mulheres (in) subordinadas: 0 empoderamento feminino e suas repercussões nas ocorrências de violência conjugal. Psicologia: Teoria e Pesquisa, v. 24, n. 2, p. 171-180, 2008.

CORTEZ, Mirian Béccheri; SOUZA, Lídio; QUEIRÓZ, Sávio Silveira de. Violência entre parceiros íntimos: uma análise relacional. Revista Psicologia Política, v. 10, n. 20, p. 227243, 2010.

DANTAS-BERGER, Sônia Maria; GIFFIN, Karen. A violência nas relações de conjugalidade: invisibilidade e banalização da violência sexual? violence in conjugal relations: concealing and taking sexual violence for granted. Cad. Saúde Pública, v. 21, n. 2, p. 417-425, 2005.

DAY, Vivian Peres et al. Violência doméstica e suas diferentes manifestações. Rev. Psiquiatr. Rio Gd. Sul, v.25, n.1, p.9-21, 2003.

DEL PRETTE, Zilda Aparecida Pereira; DEL PRETTE, Almir. Habilidades sociais e análise do comportamento: Proximidade histórica e atualidades. Perspectivas em análise do comportamento, v. 1, n. 2, p. 104-115, 2010.

FALCKE, Denise et al. Violência conjugal: um fenômeno interacional. Contextos Clínicos, v. 2, n. 2, p. 81-90, 2009.

FERRANTE, Fernanda Garbelini; SANTOS, Manoel Antônio; VIEIRA, Elisabeth Meloni. Violence against women: perceptions of medical doctors from primary healthcare units in the city of Ribeirão Preto, São Paulo. Interface - Comunic., Saude, Educ., v.13, n.31, p.28799, out./dez. 2009.

FONSECA, Denire Holanda; RIBEIRO, Cristiane Galvão; LEAL, Noêmia Soares Barbosa. Violência doméstica contra a mulher: realidades e representações sociais. Psicologia \& Sociedade, v. 24, n. 2, p. 307-314, 2012.

FOUCAULT, Michel. Vigiar e punir (1970-1975). Petrópolis: Vozes, 1987.

GADONI-COSTA, Lila Maria; DELL'AGLIO, Débora Dalbosco. Mulheres em situação de violência doméstica: vitimização e coping. Gerais: Revista Interinstitucional de Psicologia, v. 2, n. 2, p. 151-159, 2009.

GADONI-COSTA, Lila Maria; ZUCATTI, Ana P. N.; DELL'AGLIO, Débora D. Violência contra a mulher: levantamento dos casos atendidos no setor de psicologia de uma delegacia para a mulher. Estudos de Psicologia, v. 28, n. 2, p. 219-227, 2011.

GARBIN, Cléa Adas Saliba et al. Violência doméstica: análise das lesões em mulheres. Cad. saúde pública, v. 22, n. 12, p. 2567-2573, 2006. 
GIFFIN, Karen. Pobreza, desigualdade e equidade em saúde: considerações a partir de uma perspectiva de gênero transversal. Cadernos de saúde pública, v. 18, p. S103-S112, 2002.

HABIGZANG, Luísa Fernanda et al. Grupoterapia cognitivo-comportamental para crianças e adolescentes vítimas de abuso sexual. Revista de saúde pública, São Paulo, SP. v.. 43, supl. 1, p. 70-78, 2009.

\section{LIMA, Daniel Costa. Homens autores de violência doméstica e familiar contra a}

mulher: desafios e possibilidades. Dissertação (Mestrado) - Universidade Federal de Santa Catarina, Programa de Pós-Graduação em Saúde Pública, Florianópolis, 2008.

LUCÂNIA, Eliane Regina. et al. Intervenção cognitivo-comportamental em violência sexual: estudo de caso. Psicologia em Estudo, v. 14, n. 4, p. 817-826, 2009.

MONTEIRO, Claudete Ferreira de Souza; SOUZA, Ivis Emilia de Oliveira. Vivência da violência conjugal: fatos do cotidiano. Texto \& contexto enfermagem, v. 16, n. 1, p. 26-31, 2007.

OLABUÉNAGA, José Ignacio Ruiz. Metodología de la investigación cualitativa. Universidad de Deusto, 2012.

OLIVEIRA, Kátia Lenz Cesar; GOMES, Romeu. Homens e violência conjugal: uma análise de estudos brasileiros. Ciência \& Saúde Coletiva, 16(5):2401-2413, 2011.

OLIVEIRA, Zélia Maria Freire. Fatores influentes no desenvolvimento do potencial criativo. 2010.

PADOVANI, Ricardo da Costa; WILLIAMS, Lúcia Cavalcanti de Albuquerque. Atendimento psicológico ao homem que agride sua parceira. Sobre comportamento e cognição, v. 24, p. 305-313, 2009.

PADOVANI, Ricardo da Costa; WILLIAMS, Lúcia Cavalcanti de Albuquerque. Estilo Parental e Ansiedade em Homens Agressores. Estudos de Psicologia.Natal, v. 16, n. 3, p. 263-269, 2011.

PASINATO, Wânia. Atendimento às mulheres em situação de violência em Belo Horizonte. $O$ desafio de construir redes de atenção às mulheres em situação de violência, p. 131-167, 2006.

PINTO, Renato Sócrates Gomes. A construção da justiça restaurativa no Brasil - o impacto no sistema de justiça criminal. Revista Paradigma, n. 18, 2011. 
PISCITELLI, Adriana. Re-criando a (categoria) mulher? In: ALGRANTI, Leila Mezan. (Org.). A prática feminista e o conceito de gênero. Campinas: IFCH-Unicamp, p.7-42, 2002.

RIBEIRO, Daine Karina Lourenço et al. Caracterização das mulheres que sofrem violência doméstica na cidade de São Paulo. Saúde Coletiva, v. 35, n. 6, p. 264-8, 2009.

ROSA, Antonio Gomes et al. A violência conjugal contra a mulher a partir da ótica do homem autor da violência. Saúde e Sociedade, v. 17, n. 3, p. 152-160, 2008.

ROVINSKI, Sonia Liane Reichert. Dano psíquico em mulheres vítimas de violência. Lumen Juris, 2004.

SAFFIOTI, Heleieth Iara Bongiovani.; ALMEIDA, Suely Souza de. Violência de gênero: poder e impotência. Revinter, 1995.

SAMPIERI, Roberto Hernández et al. Metodologia de pesquisa. 2006.

SANTOS, Milena do Carmo Cunha. Eu ser um homem feminino não fere meu lado masculino: percepções e socializações nos grupos reflexivos de gênero para homens. Dissertação (Mestrado) - Universidade Federal do Rio Grande do Sul, Porto Alegre, 2012.

SARDINHA, Aline; FALCONE, Eliane Mary de Oliveira; FERREIRA, Maria Cristina. As relações entre a satisfação conjugal e as habilidades sociais percebidas no cônjuge. Psicologia: Teoria e Pesquisa, v. 25, n. 3, p. 395-402, 2009.

SELIGMAN, Martin. Florescer: uma nova compreensão sobre a natureza da felicidade e do bem-estar. Rio de Janeiro: Objetiva, 2011.

WOOD, Julia. Monsters and victims: Male felons' accounts of intimate partner violence. Journal of Social and Personal Relationships, v. 21, n. 5, p. 555-576, 2004.

Recebido em: 26/08/2015 Aprovado em: 20/09/2016

Universidade do Estado de Santa Catarina - UDESC Centro de Ciências Humanas e da Educação - FAED

Revista PerCursos

Volume 17 - Número 35 - Ano 2016 revistapercursos@gmail.com 